\title{
Corpus
}

Archivos virtuales de la alteridad americana

Vol. 9, No 2 | 2019

Julio / Diciembre 2019

\section{El represor como antropólogo: apuntes para la lectura etnográfica de un manuscrito contrainsurgente}

The repressor as anthropologist: notes for reading ethnographically a counter insurgency's manuscript

\section{Mariana Tello Weiss}

\section{OpenEdition}

\section{Journals}

\section{Electronic version}

URL: http://journals.openedition.org/corpusarchivos/3092

ISSN: 1853-8037

\section{Publisher}

Diego Escolar

\section{Electronic reference}

Mariana Tello Weiss, «El represor como antropólogo: apuntes para la lectura etnográfica de un manuscrito contrainsurgente », Corpus [En línea], Vol. 9, No 2 | 2019, Publicado el 27 diciembre 2019, consultado el 28 diciembre 2019. URL : http://journals.openedition.org/corpusarchivos/3092

This text was automatically generated on 28 December 2019. 


\section{El represor como antropólogo: apuntes para la lectura etnográfica de un manuscrito contrainsurgente ${ }^{1}$}

The repressor as anthropologist: notes for reading ethnographically a counter insurgency's manuscript

Mariana Tello Weiss

\section{EDITOR'S NOTE}

Fecha de recepción del original: 07/08/2019

Fecha de aceptación para publicación: 09/10/2019

\section{Introducción}

Con Freud, sin Freud, a veces contra él, Mal de archivo recuerda sin duda a un síntoma, un sufrimiento, una pasión: el archivo del mal, mas también aquello que arruina, deporta o arrastra incluso el principio de archivo, a saber, el mal radical.

Jaques Derrida, Mal de archivo

En el presente artículo me propongo analizar etnográficamente el documento titulado "Contrainsurgencia a partir del accionar del partido revolucionario Montoneros" el cual complementa y enmarca de modo singular un proyecto de investigación mayor ${ }^{2}$, centrado en las experiencias vividas en los Centros Clandestinos de Detención durante la última dictadura militar en Argentina (1976-1983), y más precisamente en el conocido como La Perla, en Córdoba. ${ }^{3}$ Para analizar las experiencias concentracionarias ${ }^{4}$ (Pollak, 2000), me he centrado hasta ahora casi exclusivamente en las memorias de los 
sobrevivientes, que se traducen mayoritariamente en testimonios (Pollak y Heinich, 2006).

2 La enorme producción de testimonios de sobrevivientes que denuncian los hechos acaecidos en esos espacios, contrasta con un número significativamente menor de testimonios de perpetradores. Los "represores" -en las categorías nativas- aunque han hablado en diferentes momentos, han mantenido un silencio estratégico, corporativo, en torno a "hechos sustantivos" (Feld y Salvi, 2019), puntualmente al destino de los "desaparecidos". ${ }^{5}$ Este silencio se complementa con la escasez de documentación que, como parte de una burocracia, produjeron a partir de su accionar "contrainsurgente". ${ }^{6}$

Originalmente catalogado en una carpeta incluida en el fondo documental "SIDE", el “caso 68" se encuentra en guarda en el Archivo Provincial de la Memoria de Córdoba. Dicho acervo forma parte del material confiscado en un allanamiento a la Secretaría de Inteligencia del Estado (SIDE) durante los años 90, por la fiscalía del Juzgado Federal N`3 a cargo de la Dra. Graciela López de Filoñuk, en el marco de las causas conocidas como "verdad histórica".

4 El fondo documental consta de dos conjuntos de documentos catalogados como "fichas" y "carpetas", con diferentes lógicas de reunión y organización de la información. Mientras las "fichas" consignan datos sobre personas y se hallan caratuladas según la identidad de las mismas, 7 las "carpetas" - un centenar de ellas - contienen información muy variopinta. Cada una constituye un "caso", 8 el cual agrupa documentación de carácter público (diarios) o reservado (escuchas telefónicas, espionaje) sobre algún grupo considerado riesgoso y sus actividades.

5 El documento que analizaré es, entonces, una rareza. Este archivo parece ser -en palabras de Olmo (2002) - subsidiario, ya que la actuación de la SIDE no fue central en la represión, al menos en el ámbito de la provincia de Córdoba, ${ }^{9}$ e hibrido, en tanto que documenta información en ocasiones proveniente de fuentes públicas, en ocasiones privadas, en ocasiones clandestinas.

6 En esa frontera entre lo público y lo clandestino debemos ubicar a nuestro documento. El "caso 68" es un documento de contrainsurgencia con apariencia de manual o apunte de un curso. A diferencia de los reglamentos y normativas, permite analizar aspectos más concretos de lo que estas fuerzas consideraban métodos "no convencionales" (Pontoriero, 2017), como los modos más eficaces de captura e "interrogación" de los secuestrados. En su primer párrafo, señala como objetivo:

...aportar mayor conocimiento de las fuerzas subversivas, no sólo en su estructura y número, sino también en su orientación política, planes de acción y líneas de pensamiento. En virtud que esto permite una apreciación mejor de las mismas y a su vez la capacidad de predecir aproximadamente de qué manera accionarán, según se den los términos del enfrentamiento.

Tratamos de esclarecer, en la medida de nuestras posibilidades, en lo que hace a metodología política, accionar militar y aspectos organizativos, incluidas las formas de funcionamiento del Partido Revolucionario Montoneros y esbozamos una metodología de contrainsurgencia, aportando un elemento más a las Fuerzas de Seguridad, para combatir en forma efectiva a las fuerzas subversivas, particularmente al PRM [Los resaltados son propios] (Caso 68, fondo documental SIDE, APM, p.1).

7 Conocer, esclarecer, predecir, para luego actuar efectivamente. La definición coincide con lo que de acuerdo con el reglamento RV-136-1 (1968, p. 225) en terminología 
castrense se entiende por inteligencia "el conocimiento de las capacidades y vulnerabilidades de los enemigos reales o potenciales, externos o internos, que de cualquier forma o procedimiento puedan oponerse a la propia conducción". En este sentido, el documento no tiene datos que hablen de personas o hechos puntuales, se podría decir que casi todo lo contrario, no se trata tanto de la sistematización de datos o información como de la elaboración de un saber ${ }^{10}$-en el sentido foucaultiano del término- sobre las "fuerzas subversivas".

Como veremos a lo largo de este artículo, el "represor", o quien fuera que fue el constructor de este documento, combina un saber -que viene de y va hacia-y un hacer a través de un (pre)decir. Un saber-hacer, un oficio, basado en un conocimiento "global" del enemigo, de sus usos y costumbres, de sus puntos débiles. Asimismo, ofrece ese saber hacer para la formación de nuevos "interrogadores". Si bien el mismo no menciona en qué consistieron los "interrogatorios" -que confrontados a los testimonios implican las torturas más atroces- sí hecha luz sobre todo un sistema de pensamiento puesto en práctica a la hora de "quebrar" al prisionero. Por lo dicho, el manuscrito permite analizar las articulaciones entre las formas de saber y las relaciones de poder (Tello, 2016) que planteó el accionar represivo, tanto como sus prácticas de escritura y archivo. ${ }^{11}$ Principio del formulario

En este sentido me pregunto ¿en qué consiste ese saber acumulado, sistematizado, que configura un protocolo de acción "contrainsurgente"? ¿Qué tipo de poderes revela? ¿Qué se hace ver, qué predecir y qué decir a través del documento? ¿Cómo este espacio de lo discursivo, plasmado en el manuscrito, puede ser tensionado, articulado, con las prácticas represivas? ¿Qué revela el mismo sobre una suerte de subjetividad represiva "contrainsurgente"? Y por último, ¿qué es lo que el documento hizo y hace? ¿Qué produce en sus lectores?

Así, este artículo se pregunta sobre la ecuación entre el saber y el poder en la práctica contrainsurgente, sobre la tensión entre la visibilidad y la invisibilidad de las mismas, y sobre su faceta productiva, performática. El análisis pretende echar luz, en definitiva, sobre los efectos que estas relaciones, plasmadas en un documento, plantean en su faceta productiva, en este caso de un necropoder ${ }^{12}$ (Mbembe, 2011). O, como señala Foucault:

...me he atenido a los textos en su aridez; he buscado su razón de ser, a qué instituciones o a qué prácticas se referían; intenté saber qué había sido de pronto tan importante en una sociedad como la nuestra para que esas vidas fuesen "apagadas" (del mismo modo que se ahoga un grito, se apaga un fuego o se acaba con un animal) (Foucault, 1990, p. 177).

\section{Aproximaciones: interrogando a un documento anónimo}

El documento tiene el título en su portada escrito a máquina y subrayado con rojo sobre papel madera. En el extremo superior derecho y sobre un rótulo de papel se lee "caso" manuscrito en azul y 68 con sellos de números. Al lado de la palabra "caso" una tachadura en negro deja entrever que anteriormente fue catalogado como "44" - con el mismo azul que "caso"-, pasando a continuación a numerarse como " 68 ". El rótulo, las tachaduras y la presencia de otro "caso 68" en la misma colección, dejan entrever la provisoriedad del orden de catalogación del acervo. En relación con su inclusión en el mismo, parece del todo fuera de serie, contrastando con los demás -que constituyen pequeñas colecciones sobre distintos grupos 
investigados- en su unicidad como texto. En su interior, el documento consta de 43 folios con numeración consecutiva: uno de carátula, dos de temario, mecanografiado en el original, todo en fotocopias (Diario de campo, mayo de 2018).

11 Teniendo en cuenta que el accionar represivo no solo eliminó a la disidencia política sino también todo rastro de su accionar criminal (Calveiro, 2006), dar con un documento de inteligencia de este estilo constituye una excepcionalidad. A su singularidad se suma que el manuscrito tiene un aspecto no muy oficial, "casero": mecanografiado y fotocopiado, reubicado en el acervo de un organismo de inteligencia al menos una vez, contrasta con otras producciones más prolijas en su edición: "reglamentos" hechos en imprenta, editados y firmados por el Ejército Argentino. El "manual", por el contrario, aparenta ser un documento interno, destinado a una circulación reducida, con instrucciones mucho más detalladas y prácticas, y cuya supervivencia y accesibilidad parece un accidente.

12 Más allá del efecto fetiche que el documento plantea ${ }^{13}$-tanto por el nivel de detalle como por su carácter secreto- tiene muchas lagunas en cuanto a su construcción como "dato" histórico. Carece de las coordenadas básicas que nos permitirían comprenderlo por completo: no está firmado ni fechado, no se le atribuye a ninguna Fuerza. Solo la caracterización de los archivos de un organismo de inteligencia y su propósito, algunas marcas internas y su rastreo en la serie documental ${ }^{14}$ nos permiten inferir algunas coordenadas espaciales, una época, algún rasgo de autoría.

¿Qué hacer - entonces- con un documento que dice tanto sobre la forma de pensar y actuar de la represión pero que al mismo tiempo tiene lagunas tan fundamentales? ¿Cómo introducirlo, con esas mutilaciones, en la gramática de la historia (Farge, 1991)? Al acceder al mismo, la sensación es la de ser un Morelli examinando un cuadro en busca de un detalle, o un Sherlock Holmes levantando del suelo un papelito olvidado en la escena del crimen, escrutando lo invisible en busca de un indicio que revele sus misterios. La "oscuridad" de lo que revela hace que tampoco se pueda leer sin tener alguna reacción física, sin ser afectado (Favret Saada, 2009). Y más allá de lo que expresa en lo textual, el documento-objeto tiene su propia aura, como la de un horrocrux. ${ }^{15}$

14 Su carácter fragmentario, tanto como su cualidad de anónimo, ${ }^{16}$ aumentan este efecto misterioso y aterrador obligando, a la hora de tornarlo inteligible, a un abordaje indiciario $^{17}$ (Ginzburg, 2003). Si bien no podemos sacar conclusiones más que parciales sobre su autoría se puede inferir que fue elaborado por alguna agencia de seguridad, ya que así nombra a las fuerzas represivas a lo largo de todo el documento, y que fue remitido a la SIDE. También se pueden inferir algunas cosas sobre su circulación, por su reubicación en el archivo y, al no ser una carpeta a la que se le agregaron folios, pareciera que tuvo una importancia que se modificó con el tiempo.

Luego, podemos inferir que su supervivencia dependió del descuido o del azar que suele haber en el Estado, "que con una mano mata y con otra escribe" (Olmo y Somigliana, 2002), de la cualidad subsidiaria del archivo local de la SIDE, y de la inocuidad del "caso 68 " en términos de prueba "clásica". En este último sentido, las prácticas que pueden constituir delitos solo pueden leerse entre líneas, los responsables de los mismos no son identificables a título individual ya que no tiene autor, tampoco nombra víctimas, e incluso recurre a los clásicos eufemismos de la jerga concentracionaria para "enfriar" en el lenguaje las prácticas más comprometedoras. Finalmente, el documento llega a manos de la justicia, y allí comienza la exégesis. 
Una aproximación analítica y pormenorizada a la globalidad del mismo, de su ubicación en un acervo mayor, de sus marcas o de la falta de las mismas, así como de la textura y pliegues de esos papeles arroja nuevas preguntas. Más allá de su aplicación judicial ¿cómo contribuye un documento de este tipo a comprender las prácticas represivas en los Centros Clandestinos de Detención? ¿De qué momento nos habla? ¿De aquel en el que era necesario formar en un método contrainsurgente o de otro en el cual había que sistematizar un "legado"? ¿Qué busca producir? Siendo consciente de que quizás nunca se tengan respuestas concluyentes a estas preguntas, el documento arroja algunas aproximaciones a la relación en torno a la ecuación saber-poder para los agentes de inteligencia, y sobre el sentido de sus prácticas en el ejercicio de ese binomio.

\section{El represor como antropólogo}

El documento consta de varias partes, ordenadas bajo el título de "temario", en el mismo se consigna:

I Objetivos

II A) Consideraciones generales

Desarrollo de la hipótesis de guerra del PRM

Características de la guerra

Instrumentación de la guerra:

En lo político

En lo militar-logístico

En lo propagandístico y psicológico

En lo organizativo

B) la respuesta de las Fuerzas de Seguridad debe ser integral

Consideraciones particulares acerca del PRM

Acerca de los movimientos y funcionamiento del PRM

Consideraciones

Asentamiento

Movimientos

Funcionamiento

Acerca del accionar militar

Consideraciones

Acción miliciano

Acción tipo comando

Acción tipo reagrupable

Acerca del accionar logístico

Consideraciones

Documentación

Abastecimiento, depósito y transporte

Talleres

Sanidad

Acerca del accionar de inteligencia

Información

Comunicaciones

En lo propagandístico

Para el ámbito nacional

Material de difusión externa

Material de difusión interna

Infraestructura

Para el ámbito internacional

En lo psicológico

IV Contrainsurgencia 


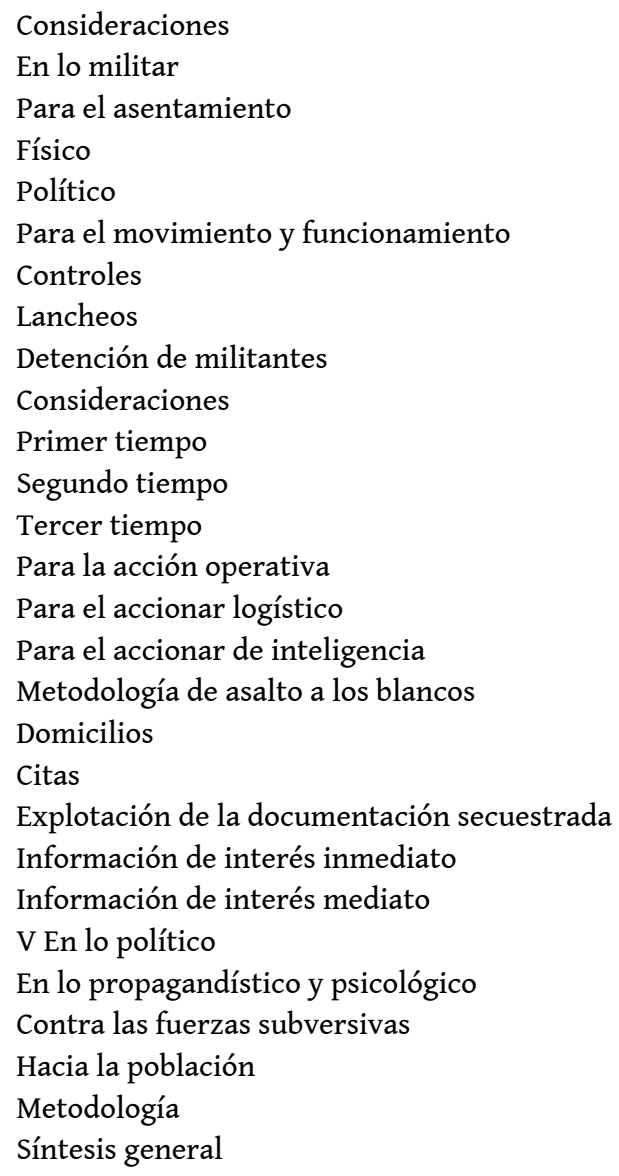

El punto IV, que analizaremos en el próximo apartado, contiene el programa de aplicación de la metodología contrainsurgente. Todo el resto - lo cual constituye una gran parte del escrito- analiza detallada y minuciosamente diferentes aspectos de la ideología y las prácticas del "Partido Revolucionario Montoneros" (PRM). ${ }^{18}$ Esto quiere decir que, antes de instruir sobre recomendaciones prácticas, el documento debe poner a las mismas en el marco de un saber sobre ese enemigo que constituyen las "fuerzas subversivas", un saber rigurosamente ordenado en ítems que construyen un temario y que va desde las representaciones sobre el enfrentamiento, pasando por sus prácticas político-militares y sus formas de subsistencia hasta llegar al modo de comunicación clandestina.

En el apartado "Desarrollo de la hipótesis de guerra del PRM", comienza por señalar los aspectos ideológicos y programáticos de la organización:

En el 'campo popular' el PRM considera definitorio y estratégico, captar al sector más enfrentado según su tesis marxista con el polo hegemónico del poder (USA); este sector sería la clase trabajadora industrial (en virtud de su relación de 'dependencia y explotación con el gran capital'). Secundariamente, trataría de captar a otros sectores que denomina genéricamente pueblo, que involucrarían a la clase obrera campesina, a los sectores de los servicios (empleados estatales, de comercio, etc.), pequeños propietarios tanto rurales como industriales y sectores del estudiantado y profesionales; todos los cuales acompañarían a la clase trabajadora en su supuesta lucha por la liberación nacional y social del país) (Caso 68 , fondo documental SIDE, APM, p.1).

Antes de seguir con el análisis del documento, detengámonos un momento en las resonancias que me provocó su lectura, las cuales motivan el título del artículo. Curiosamente, la elaboración del índice, la descripción minuciosa del mundo de los 
militantes que propone la primera parte del manuscrito tuvieron, desde mis primeras lecturas un -incómodo- aire de familiaridad. $Y$ es que, sin los recursos estilísticos que caracterizan a la etnografía, pero no por eso con menos densidad en la descripción, el manuscrito muestra, podríamos decir, el ethos y la cosmovisión (Geertz, 2000) de la organización Montoneros, su visión sobre el mundo en aquel momento, sus divisiones, sus hipótesis de conflicto, los actores principales del mismo. La analogía usada en el título -y que tomo prestada de Carlo Ginzburg en su análisis sobre las actas inquisitoriales- tiene que ver, entonces, con la sorpresa de encontrar en un documento de inteligencia una descripción no solo acertada de las prácticas militantes, sino una comprensión de su sentido, tan similar a la que me había llevado años en la escritura de una tesis doctoral. ${ }^{19}$ Planteadas las -inquietantes- similitudes, sobrellevada la incomodidad, las diferencias entre antropólogos y represores son bastante obvias en cuanto a sus objetivos últimos. ${ }^{20}$ Reflexivamente, sin embargo, resulta interesante plantear la resonancia y el desconcierto de reconocer un saber ya formulado y sistematizado cuasi etnográficamente 40 años atrás.

21 Dicho esto, continuemos con el análisis. Tras ofrecernos lo que podría ser la "estructura de la vida tribal" en su índice, ${ }^{21}$ destaca que el PRM se organiza en un Partido y un Ejército y que, aunque no descarta la vía democrática como un modo de acceder al poder, privilegia en este sentido la vía militar. En consonancia, en el apartado "Características de la guerra", analizará sus hipótesis de conflicto en términos de "guerra", una "guerra"22 que -según los agentes de inteligencia- se da en todos los frentes y cuyo objetivo es el cambio "integral de nuestro sistema de vida". El nosotros inclusivo lógicamente coloca a los autores del documento en el lugar de defensores de ese sistema y, en reiteradas ocasiones, habla de las "fuerzas de seguridad" como las encargadas del "combate". Asimismo, caracteriza lo que la organización entiende por "pueblo", por "sectores nacionales" y el rol como "vanguardia" que se adjudican en la lucha al liderar a las "masas".

Realizando un análisis ideológico - muy acertado por cierto-, de lo que esta organización entendía como "pueblo" (la clase obrera industrial) y como "nación" (una burguesía local que no necesariamente es "popular" pero puede ser captada para la causa, dado su "ahogo" por parte de los monopolios), así como de sus principales líneas de acción tanto políticas como militares, el documento pasa a analizar los lugares privilegiados de "infiltración" de la subversión (sectores obreros y estudiantiles) y las zonas prioritarias en tanto asentamientos de ambos grupos (Córdoba y La Plata).

La palabra "infiltración", que en el contexto del documento refiere a las prácticas políticas de los movimientos revolucionarios al insertarse en diferentes sectores sociales, es interesante. La misma no solo supone una vinculación "de encubierto" sino que - presuponiendo a estos movimientos como "ajenos" a los sectores que buscan captar- se vuelve fértil para analizar el juego de identificación y alteridad, de exclusión e inclusión dentro de ciertas categorías en disputa entre las organizaciones y las fuerzas de seguridad como "pueblo", "obreros" o "estudiantes". Mientras que en las organizaciones la palabra "infiltrado" ${ }^{23}$ (o "filtro") refería a agentes de las Fuerzas que actuaban de encubierto (Tello, 2012), en el contexto del documento la categoría "infiltración" refiere tanto a lo ajeno de estos "elementos" respecto a los grupos sociales que buscan "captar", como en el carácter velado de esa acción, acorde a la caracterización de las doctrinas contrainsurgentes sobre el "enemigo" (Pontoriero, 2017). Así, la "infiltración" es una categoría versátil y especular que permite pensar el 
juego de identificación y alteridad (Krotz, 1994): para el documento los militantes por momentos son y por momentos no son miembros de los grupos cuya adhesión se disputan en la "guerra" (sobre todo de la categoría "pueblo"); pudiendo esto también ser un indicio de la identidad del autor. ${ }^{24}$

El documento incluso analiza tipos de militantes, jerarquías y capacidad militar en relación con el entrenamiento recibido, los grados de compromiso dentro de la organización y lo que esto implica en términos de "peligrosidad" pero también de potencialidad. Potencialidad que se "explota" más adelante, cuando pasa al apartado de contrainsurgencia, vinculado a la obtención de información. Este punto es vital en su tratamiento posterior ya que, en el manual los militantes son, más que un peligro real -ya que se dedican tan solo unas líneas en la sección que habla del "lancheo" 25 a prevenir "bajas" en las filas propias a partir de esas acciones de "combate"-, potenciales "fuentes" de información.

En el apartado III "Consideraciones particulares acerca del PRM" el análisis se pone todavía más "interesante" en relación al nivel de detalle de ese saber global. Con respecto al "asentamiento" de los militantes, por ejemplo, describe:

...se intenta siempre buscar una casa y no un departamento, que se alquile o venda por un particular y no por inmobiliaria. La casa preferentemente debe tener fondo, buena vía de escape, garaje y una pieza más que la necesaria para que la gente que la habita. La misma debe mantenerse limpia y cuidada (Caso 68, fondo documental SIDE, APM, p. 12).

Una vez más, cual antropólogo, el represor describe minuciosamente las características de la domesticidad de los militantes. El documento muestra, a fines de "detectarlos", un grado de conocimiento enorme sobre cómo funcionaban las vidas públicas, clandestinas y privadas de los militantes. La información "estratégica" va desde el conocimiento de todos los tipos de asentamientos, casas y hábitos domésticos, pasando por la posibilidad de "ampliar el rango de investigación" a las familias -especialmente personas mayores y niños- hasta llegar a la "colaboración" de los vecinos en la detección de los mismos indicios sistematizados en el manuscrito.

Además de su asentamiento, conocen a la perfección las prácticas clandestinas: las "citas" que realizaban los militantes y los medios por las cuales se contactaban, sus actividades cotidianas, sus modos de vivir, la organización de las viviendas, los barrios que elegían, a sus hijos. El "efecto panóptico" ${ }^{26}$ de este apartado es abrumador, ya que parecen mirar no solo sobre el territorio y dentro de las casas, sino también de las mentes de los militantes. Con esto me refiero a que las acciones tanto políticas como logísticas o militares, no son solo descriptas, sino que son cabalmente comprendidas en su sentido.

El colaborador una vez integrado como activista es preparado, primero en términos político-ideológicos y disciplinarios (puntualidad, forma de vida acorde al proyecto, trabajo político en el frente correspondiente, etc.). Una vez asegurado el cumplimiento de estos requisitos se comienza con la instrucción militar, de tipo milicias (llamada paramilitar). De acuerdo a la respuesta dada por el militante se le va exigiendo más, hasta lograr el nivel de preparación política, ideológica y militar que permite evaluarlo como miembro pleno del partido (oficial en la actualidad; hay propuesta de integrar al nivel de Aspirante como miembros plenos del partido (Caso 68, fondo documental SIDE, APM, p. 5).

Queda claro, en la descripción, la comprensión de todo un mundo de jerarquías y requisitos para la movilidad dentro de las organizaciones, así como de la aptitud política y moral esperada en cada caso. También qué acciones correspondían a la 
iniciación en cada nivel de los militantes, qué relación había entre estos rituales de paso (Turner, 1990) y los grados de "compromiso" de los mismos, la relación que se va haciendo carne en cada sujeto entre lo ideológico, lo político y lo militar y -lo más importante, ya que luego es clave a nivel pragmático- sus características como ethos.

Ethos y cosmovisión de la cultura militante quedan completamente claras a lo largo de esta primera parte del documento, tanto que, como señalé al principio, el represor parece un etnógrafo avezado. Esto permite pre-decir aspectos prácticos y programáticos del grupo en cuestión.

Un punto interesante es la claridad sobre el hecho de que, aunque se la llamara "guerra", la verdadera disputa se daría en el terreno político: en torno a las repercusiones que tendrían las acciones del PRM o las propias a la hora de captar la simpatía popular. En este sentido, a lo largo de todo el manual la "población", encarnadas en general por los "vecinos" como sujeto, son construidos como referencia del sentido de las acciones de las propias Fuerzas en un interesante juego entre visibilidad y clandestinidad de las prácticas represivas, y de gestión de los afectos. En relación a esto último, constantemente recomiendan la "cordialidad" en el trato durante operativos en la vía pública y el apremio solo puertas adentro. En lo que denomina aspectos "político-tácticos" en lo relacionado con los procedimientos "rastrillo" 27 y a los "allanamientos", señala:

C2019-11-05T17:51:00CCuando se va a copar una manzana para el asalto a una casa no es necesario y por el contrario, es contraproducente, el mal trato con los vecinos (aunque sea de palabra) (...) el buen trato no significa falta de firmeza (...) incluso puede aprovecharse la situación de enfrentamiento para explicar a los vecinos el porqué de las circunstancias que se ven obligados a vivir, lo que en definitiva redunda en el logro de la confianza por parte del conjunto hacia las fuerzas de seguridad (Caso 68, fondo documental SIDE, APM, p. 41).

31 En el párrafo transcripto, se puede observar, además del control territorial, las características performativas de ese control. El territorio, los "vecinos" -categoría equivalente a lo que luego sería calificado de "sociedad", los que no eran ni militares ni militantes- son objeto de disciplinamiento, no solo por la situación de "copamiento por asalto", y la consiguiente presencia de uniformados portando armas, que proceden a detener personas. La recomendación de un trato cordial pero no por eso "falto de firmeza", la explicación del "porqué de las circunstancias que se ven obligados a vivir", legitima su accionar, pone en escena un poder que se entiende a sí mismo como destinado a "salvar" a la patria por los medios que sean necesarios. También - por qué no- reafirman aquel antiguo imaginario de las Fuerzas Armadas como "reserva moral de la nación", que viene a "poner orden" ante el "caos" sembrado por la guerrilla o a llenar el "vacío de poder" de los gobiernos democráticos (Calveiro, 2001).

Este juego de construcción de cara a la población de una alteridad radical respecto a los militantes e identificación hacia las Fuerzas Armadas, es lo que atraviesa todo el apartado referido a las recomendaciones "en lo político", ${ }^{28}$ donde, si los vecinos son llamados a "colaborar", se sugiere lo propio con otros sectores prioritarios para la "infiltración marxista":

Otro aspecto táctico-político es impedir la infiltración del PRM en las fábricas, universidades y organismos de masas barriales, a través de la prohibición del accionar de las comisiones internas, centros de estudiantes, cuerpos de delegados (hasta el logro del aniquilamiento de las Fuerzas Subversivas). En lo que hace a los organismos de masas barriales, se debe realizar un severo control sobre sus miembros y las actividades que estos realizan. 
También es importante, como complemento del accionar de aniquilamiento de las Fuerzas Subversivas, un bloqueo o destrucción de todas las organizaciones o partidos políticos que, aun siendo legales, se convierten en retaguardia (Caso 68, fondo documental SIDE, APM p. 41).

En las instrucciones táctico políticas al respecto aparece, aunque no nombrada de ese modo, una metodología represiva mencionada por los militantes que entrevisté como una política de "cerco y aniquilamiento", ${ }^{29}$ que llevaría a la "derrota" de las organizaciones. "Derrota" debida tanto al masivo "aniquilamiento" físico de los militantes - percibidos por las fuerzas represivas como "vanguardia" y autopercibidos de ese modo por parte de las organizaciones- sino por el control capilar ejercido dentro de todas las organizaciones políticas y el potencial aterrador de la indiscriminación de los "blancos" que integraran la "retaguardia".

Esa "retaguardia" fue de hecho, y por su mayor exposición pública, un importante blanco de la represión. Estadísticamente, para el caso de Córdoba, la detención de activistas sociales y gremiales, así como de "colaboradores" -familiares, abogados que realizaban gestiones de averiguación ante las desapariciones- es elevada, y corresponde a los primeros tres meses tras el golpe de Estado del 24 de marzo de 1976 y a la última, luego del año 78, donde son detenidos sobre todo abogados (Dossier Mega Causa "La Perla" 2012).

El documento tiene unas pocas marcas temporales ${ }^{30}$ por las cuales se podría inferir que fue confeccionado a partir de la segunda mitad del año 1976. Para ese momento, la represión había ya secuestrado a todo aquel que tenía una actividad "de superficie"; respecto de los militantes de organizaciones clandestinas, los agentes de inteligencia quizás no tenían claro dónde vivían todos los militantes, pero sí cómo. Tenían claro cuáles serían los objetivos privilegiados y las prácticas militares que emplearían, cómo se retirarían y cómo atenderían a los heridos. Sabían hasta qué tipo de apoyo tenían en el exterior del país, sabían lo que significaba para ellos la muerte propia o de un compañero.

Pero más allá de disputar cabalmente el sentido performativo (Bourdieu, 2002) de la violencia ejercida por ellos mismos o por sus contendientes, los agentes de inteligencia conocían el dilema moral que entrañaba la "violencia revolucionaria" para los propios militantes como un "mal necesario"; y el enorme esfuerzo que los mismos habían hecho para desandar los contratos civilizatorios (Elias, 2001) en que habían sido socializados.

En ocasiones el represor incluso repara en aspectos velados hasta para los propios cuadros "medios" de las organizaciones, como la totalidad de la estructura de la organización o su real poder de fuego. Tenían clara su forma de ver el mundo, y sus "debilidades" políticas y militares, pero sobre todo humanas. Conociendo el fin de la historia, este saber-hacer que conformó el "arte de quebrar" a los militantes "detenidos" -en realidad secuestrados, desaparecidos- hizo del método represivo empleado algo no solo efectivo en el exterminio, sino eficaz a la hora de instalar una larga cadena de disciplinamientos que, mediante la instalación del terror y la sospecha, perdura hasta la actualidad. En un párrafo dedicado a la "acción psicológica" ${ }^{11}$, refiriéndose a la organización Montoneros, señala:

Internamente se trata de crear toda una mística alrededor de la muerte heroica, de la necesidad de no dar información al ser detenido, haciendo hincapié [en] la imposibilidad de salir con vida una vez en manos de las Fuerzas de Seguridad, aunque medie por parte del militante una colaboración total hacia estas. 
Por otra parte, [se trata de crear] toda una mística en lo que se refiere a la invencibilidad de las 'fuerzas populares', en especial su supuesta vanguardia (Caso 68 , fondo documental SIDE, APM, p.8). holista en el que los agentes de inteligencia lo analizan los vuelve capaces de comprender - dentro del ethos y la cosmovisión del grupo- los alcances del riesgo de "caer". La visión - una vez más muy acertada- de la "mística alrededor de la muerte heroica", de ese don de sí que implicaba "no caer con vida" (Tello, 2018), privilegiando la organización y "la causa" sobre la propia supervivencia, es harto comprendida por los represores. Y las consecuencias de su no consumación, también.

La consigna es no caer vivo, la función de esto es evitar que el militante aporte cualquier tipo de información a las Fuerzas de Seguridad. Obviamente, ante el hecho de caer vivo existe la orden de no dar ninguna información ya que en el caso de así hacerlo le cabe al militante el calificativo de traidor y consecuentemente la pena de fusilamiento. Otro aspecto táctico-político es impedir la infiltración del PRM en las fábricas, universidades y organismos de masas barriales, a través de la prohibición del accionar de las comisiones internas, centros de estudiantes, cuerpos de delegados (hasta el logro del aniquilamiento de las Fuerzas Subversivas). En lo que hace a los organismos de masas barriales, se debe realizar un severo control sobre sus miembros y las actividades que estos realizan.

También es importante, como complemento del accionar de aniquilamiento de las Fuerzas Subversivas, un bloqueo o destrucción de todas las organizaciones o partidos políticos que, aun siendo legales, se convierten en retaguardia (Caso 68, fondo documental SIDE, APM p. 25-26).

El uso del término "dar" hace, performa, en el discurso escrito, su propio efecto creador de estigmas. El militante que "cae" y "da" información es considerado un "traidor" y está doblemente condenado a muerte, tanto por su organización como por sus captores. Entre opciones malas y peores en la situación de secuestro, la connotación voluntaria con la que se califica ese "dar" información o "no llegar a dar la vida", no hace sino prever, para el futuro, los efectos de esa "traición" como algo que podría haberse evitado.

El conocimiento "psicosocial" de los agentes de inteligencia analizado hasta ahora se complementa con lineamientos muy concretos en este sentido, destinados a capturar y obtener más información para alimentar dicho poder cuando el militante se ha convertido en militante detenido, o simplemente en detenido. De la lectura integral de las "líneas de pensamiento de las fuerzas subversivas", se desprende un "planteo estratégico" que "obliga a las fuerzas de seguridad a dar una respuesta global y acorde" para llegar a actuar en consecuencia, señalando que "en términos de guerra, lleva a dar una respuesta en lo político, en lo económico social, en lo militar y en lo cultural" (p. 9).

Una vez más, sabiendo ya el final de la historia, toma toda otra dimensión lo que algunos de los militantes entrevistados para mi tesis doctoral manifestaron cuando señalaban, refiriéndose a los represores, que "los subestimaron". Se trató de una violencia que difería en lo cualitativo de la planteada por los militantes, una violencia deshumanizante, cruel.

Como ocurre con cierta antropología criminal aplicada por las fuerzas de seguridad creo pertinente señalar que, en ocasiones, los cientistas sociales también subestimamos estas formas de saber, creando un efecto de alteridad radical respecto a ellas por la aversión ética que nos generan. Las diferencias entre un represor y un antropólogo en los propósitos de su investigación son evidentes en sus fines y en sus métodos, pero por lo mismo, y al decir de Ginzburg, vale la pena analizar las similitudes. Más adelante, en 
el apartado "Contrainsurgencia", las diferencias entre el antropólogo y el represor quedan del todo claras. A diferencia del antropólogo el agente de inteligencia conoce para doblegar - trayendo una vez más a la memoria a Ginzburg, y al análisis de la documentación inquisitorial-, busca una verdad, y lo hace a través de suplicio.

\section{La "contrainsurgencia" y sus resonancias}

Personalmente, tomé contacto con este documento en 2008, a partir de los alegatos de la asociación H.I.J.O.S. ${ }^{32}$ en la causa conocida como "Brandalisis". Durante ese juicio $-\mathrm{y}$ los que siguieron- la principal estrategia de la defensa fue acusar a los sobrevivientes constituidos en testigos, y en particular a un tipo de sobrevivientes obligados a realizar diferentes tareas al interior de los Centros Clandestinos de Detención, de "colaboradores". La estrategia, esbozada en el documento e implementada con eficacia mientras el "campo" funcionó como tal, se reproducía también eficazmente en la escena judicial. Si bien los sobrevivientes, y en particular aquellos considerados "testigos clave" por su permanencia prolongada en el campo y por el hecho de haber pasado una parte del cautiverio sin venda, contaban con una autoridad testimonial de hecho, la misma se veía constantemente tensionada desde el punto de vista ético al ser acusados de "colaboradores", es decir, de "traidores".

En ese contexto, el "caso 68" formó parte de la prueba ofrecida por la querella de H.I.J.O.S. y Familiares de Desaparecidos y Detenidos por Razones Políticas, sobre la sistematicidad del método de "quiebre" como parte de una estrategia contrainsurgente y no -tal como proponía la defensa- como un producto de la voluntad de los prisioneros. Más adelante, habiendo colaborado en el acompañamiento de los testigos como parte del área de investigación del Espacio para la Memoria "La Perla", volví a familiarizarme con este documento a la hora de fundamentar ciertas posiciones en torno a los sobrevivientes-testigos, devenidos testigos-víctimas en el marco de la "Causa Acosta". 33

Los sentidos atribuidos a la palabra "colaborador" son un fiel reflejo de la caracterización del universo concentracionario como un mundo "invertido" (Pollak, 2006) y del poder de la nominación (Bourdieu, 2002). Si en nuestra vida cotidiana "colaborar" tiene un sentido positivo, en el universo concentracionario se torna un eufemismo que alude a ayudar a los represores a lograr su cometido "dando" información para generar nuevos secuestros. El dejo de voluntad que deja entrever la palabra desplaza la responsabilidad del entorno de terror o del método represivo a la víctima, volviéndola, en sus comunidades de origen, un "traidor". Durante décadas, esta fue la explicación que fundamentó la defensa de los represores, y también el fuego cruzado entre víctimas, la acusación de unos a otros de haber generado "caídas", desgracias. Y aquí es cuando, al revelar su intención en tanto método, al dejarlo por escrito, nuestro documento adquiere centralidad. ¿Cómo se configuró, entonces, esa identidad de "colaborador"? ¿Qué revela la práctica de escritura y archivo al respecto?

En el apartado IV "Contrainsurgencia", detalla una serie de ítems que tienen como objetivo último lograr la captura con vida de los militantes, y como objetivo último de esta el "quiebre". Como fundamentación de la estrategia "contrainsurgente" -es decir clandestino y basado en métodos "no convencionales" - señala:

C2019-11-05T17:53:00CEn virtud de que las Fuerzas de Seguridad se ven obligadas a llevar adelante una guerra no convencional por el propio accionar del PRM es 
condición necesaria que esta lucha sea de aparato contra aparato y en la medida de lo posible dentro de la clandestinidad. De esta manera se bloquea un aspecto importante de la estrategia del PRM que es la pretensión de lograr que las Fuerzas de Seguridad aparezcan como opresoras de la población [Subrayado en el original] (Caso 68, fondo documental SIDE, APM, p. 26). punto B.3 habla de la detención del militante:

La caída del militante es el objetivo primordial de la contrainsurgencia, más si se lo logra detener vivo. Una vez obtenido esto, el logro de su colaboración permite la caída de otros militantes, infraestructura y de la colaboración de índole estratégica (Caso 68, fondo documental SIDE, APM, p.32).

Aquí puede verse que el objetivo no es solo exterminar, sino más bien disciplinar, volver útil y dócil (Foucault, 2002) al militante capturado a fin de lograr más “caídas". La "colaboración", subrayada en el original, era en concreto lograda por una serie de tecnologías represivas en las que la tortura física es solo una parte. Dije anteriormente que los represores, más allá de entender ideológicamente el mundo de los militantes, lo 
comprendían también ética y afectivamente, usando esto a su favor para doblegar su voluntad. Esto, en concreto, se refleja en una serie de situaciones que prescribe como metodologías y que, en la práctica, hacía que los prisioneros desandaran de un modo abrupto, mediante un terror que alcanzaba su integridad y la de otros, no solo los preceptos civilizatorios en los que habían sido socializados, sino el ethos de sus propias organizaciones.

En este punto el agente de inteligencia organiza la exposición no en torno a la práctica del "interrogatorio" - completamente omitida- sino a la importancia del tiempo como variable en la aplicación del método. Señala:

Otro aspecto fundamental, referido a la validez de la colaboración, está dado por el tiempo en el que se logra esta. Este es de vital importancia, ya que como se ha visto en los puntos correspondientes, la relación escalonada y la dinámica con la que se realizan los controles, lleva a que después de un plazo de tiempo, que es corto, la información obtenida en gran parte pierda efectividad (sobre todo en lo que hace a la caída de otros militantes) (Caso 68, p.32, Fondo documental SIDE, APM).

Así, dividen los tiempos del "interrogatorio" en tres tiempos, donde el primero es el fundamental para lograr más detenciones:

La interrogación con métodos no ortodoxos es desde ya en función de la rapidez con la que debe cumplirse el $1^{\circ}$ tiempo, necesaria e imprescindible pero se hace mucho más eficaz si se acompaña de toda una ambientación en función del quiebre (Caso 68, p.32-33, Fondo documental SIDE, APM).

Los métodos "no ortodoxos" de interrogación remiten -en base a lo relatado por cientos de testigos- a la aplicación de tormentos como ritual de iniciación (Turner, 1990) dentro del universo concentracionario. El apremio (en la doble acepción de la palabra) que caracteriza este momento, las 48 horas que los militantes tenían previstas para "levantar" todo ante la caída de un compañero, justifica, desde la perspectiva de los represores, el uso de esos métodos "no ortodoxos" de interrogación. Sin embargo, el agente de inteligencia es muy consciente de que la verdadera eficacia del método es a largo plazo, y no solo a través del dolor físico. El objetivo es el "quiebre", "romper" a la persona.

El contraste de lo dicho en el documento con los testimonios de sobrevivientes, la conjunción de las dos perspectivas es por demás iluminadora. Respecto de la “ambientación", un sobreviviente relata:

La tortura con el palo fue algo terrible; "Texas" ${ }^{34}$ creaba una verdadera escenografía terrorífica. El tormento comenzó cuando fui llevado a una oficina, con las manos atadas por delante de mi cuerpo. Me sacaron la venda de los ojos y entonces "Texas" comenzó a apalearme precisa y rítmicamente con un palo de madera similar a los de la policía, mientras decía; "Quiero una casa, una casa... un nombre, un nombre...". A cada pregunta y a un ritmo de uno por segundo, aproximadamente, un palazo.

No era un golpe brutal, sino medido pero contundente. Los blancos preferidos eran las articulaciones de las manos, codos, hombros, brazos, rodillas, canillas, tobillos y la cabeza, es decir todos los lugares donde los huesos son muy superficiales. Como no tenía los pies atados yo trataba de esquivar los golpes corriendo por la habitación, pero era imposible escapar al castigo. Estaba rodeado de otros torturadores, y cuando tropezaba y caía me arrojaban al centro de la habitación otra vez, como a la jaula de un león. Así, fui cayendo cada vez más seguido. Y cuando me levantaba, una nueva zancadilla me arrojaba al piso. Comencé a desfallecer mientras los palazos continuaban al mismo ritmo, al igual que los gritos de "Texas" y sus secuaces. Finalmente caí y no pude levantarme. Entonces me 
sostuvieron entre varios hasta que me desvanecí (Gustavo Contepomi y Patricia Astelarra, Sobrevivientes de La Perla, El Cid Editor, abril de 1984). características de aquel primer momento en el Centro Clandestino:

La llegada del secuestrado con el bagaje de información que pudiera acumular en su cabeza (la cual había que sacar por cualquier medio y lo más rápidamente posible), era considerada como "una fiesta" por el conjunto del personal militar y civil de La Perla.

Todos rodeaban al detenido al cual se interrogaba vendado. Primero se lo intentaba "ablandar" hablándole del rol que cumplían los oficiales jóvenes como salvadores de la Patria, o bien se utilizaban golpes de puño, palos, patadas, amenazas, gritos, etc. Durante bastante tiempo, las paredes de las oficinas mostraron las manchas de sangre seca o marcas de pisadas. Posteriormente el detenido era llevado a la "sala de terapia intensiva" (Testimonio de Teresa Meschiati, Legajo CoNaDeP 4279, diciembre de 1983).

57 Este primer tiempo del recién llegado también incluye -en las instrucciones del manual- además de la tortura y el "adoctrinamiento", el "lancheo", el cual sella, en un mismo movimiento, su efectividad en términos pragmáticos (llevar a los militantes a las "citas" que tenían ese día, detectar a otros militantes, producir nuevos secuestros) y su efecto afectivo dado por el sufrimiento ante la "caída" de otros, y una serie de emociones morales que "rompen" a la víctima: como la vergüenza, la culpa, la humillación. Una vez en el universo concentracionario esto no cesaba, ya que se trataba de una rutina de más sufrimientos, más torturas, más "caídas" y una condena a muerte que solo variaba en su plazo de concreción. Se puede entender entonces que la tortura, así entendida, forje una subjetividad "vaciada", tal como la caracterizan los sobrevivientes.

Si el primer tiempo implica un dolor físico, psíquico y moral, el segundo tiene un efecto que profundiza el terror. En el documento se menciona que en ese momento hay que pasar a interrogarlo sobre su actividad, pero mostrando al mismo tiempo que ya saben "todo", para lo cual, es de utilidad, por ejemplo, tener un organigrama que muestre, gráficamente, la ubicación del recién llegado dentro de la organización y de su actividad. Esto para llegar al tercer tiempo, momento cúlmine, que denomina "política de colaboración":

Todo el accionar dirigido hacia el detenido debe tener como logro su colaboración, desde el primer momento. La colaboración de los detenidos debe ser el factor más débil con que cuenta el PRM o cualquier otra organización subversiva, ya que esta actitud vulnerabiliza en gran parte el aparato, ya sea sus miembros como sus planes de acción, en síntesis, su estrategia global de guerra (Caso 68, p.33, Fondo documental SIDE, APM).

La "colaboración" - y yo agregaría la implantación de la misma como razón de la "derrota"- es el mayor punto débil ya que vulnerabiliza, en un doble vínculo, a la organización y a sus miembros. Respecto a esto señala como acciones tendientes a doblegar su voluntad:

-como ya hemos dicho a demostrarle al detenido que se tiene información concreta sobre su actividad.

- el encuentro con otros detenidos que le dicen por ejemplo "hola como te va", destabicados (por supuesto no el lugar) ya que se supone que el militante detenido tiene dos alternativas: o colabora en forma plena (lo que lo convierte, a través del tiempo, en una persona de suma confianza), o no siendo así pasa a sufrir las consecuencias de los términos en los que el PRM obliga a plantear esta guerra, por 
lo que el destabique, en ninguno de estos dos casos, implica un problema de seguridad; lo que lleva a lo que en general el militante considera a quienes se les presenta, como muertos, el hecho de encontrarlos vivos y colaborando le cree una contradicción inevitable (que es la posibilidad de vivir, ante la muerte segura que le vaticinaba el PRM) lo que apresura notablemente el quiebre.

- además los militantes con el detenido debe encontrarse, han de ser colaboradores e instarlo a declarar en forma voluntaria.

Esto no significa que todo militante se quiebre con este método, pero sí hace que su posterior interrogación sea más fructífera, con resultados más rápidos y espectaculares.

Este logro, en el primer momento, va a incidir notablemente en toda la actitud posterior del detenido en lo que hace a la colaboración [el resaltado es propio]

(Fondo documental SIDE, APM, Caso 68, p.34).

Como tecnología de poder, el "arte de quebrar" - dice el instructor- produce resultados que pueden ser espectaculares. Y esto es porque, para la destrucción de proyectos políticos, destruyeron el andamiaje temporal, espacial y sobre todo moral que hace a la continuidad sincrónica y diacrónica del yo (Pollak, 2006). Destruyeron el horizonte de posibilidades y el sentido compartido del mundo que los militantes tenían, la dimensión de su propia "voluntad", y ante todo las expectativas mutuas que hacen a la estabilidad social que en situaciones normales es la base del sentimiento de "confianza".

Liliana Callizo, sobreviviente de La Perla, relata:

La aplicación de la tortura dependía de una planificación represiva, con el principal objetivo de lograr información y destruir, por medio de la denigración, el menosprecio, la incertidumbre y el miedo, la destrucción del ser humano. Intentaban cambiar con los golpes y la continua presión sicológica, los valores morales, sociales, políticos de los secuestrados (Testimonio de Liliana Callizo ante el Consulado Argentino en Bilbao, España, marzo de 1984).

62 Las prácticas concretas, los "detalles" de lo que en concreto implicaba el método, presentes en los testimonios de los sobrevivientes, constituyen una nueva producción de escritura, un nuevo régimen de visibilidad. Esas escrituras son reveladoras tanto de la crueldad de lo que subyace al eufemismo de la "colaboración", como de la capacidad de las víctimas para reordenar y dotar de algún sentido a las escenas dantescas que componen las memorias sobre la experiencia concentracionaria.

Escritura de doble filo que, a la vez que revela y denuncia, espanta.

\section{Conclusiones}

64 A lo largo de este artículo he analizado el documento "Contrainsurgencia a partir del accionar del partido revolucionario Montoneros", que consta en una carpeta del fondo documental "SIDE", en guarda en el Archivo Provincial de la Memoria, en Córdoba. A pesar de sus cualidades fragmentarias y carentes de los datos con los que una historiografía o una antropología más bien positivista permitirían entramarlo en la gramática de la historia de la represión, el mismo da cuenta de un afán de sistematización de un saber y una visibilización de las prácticas "contrainsurgentes" llevadas adelante dentro y fuera de los Centros Clandestinos de Detención.

65 Me he preguntado, a lo largo del artículo, qué es lo que el documento hace ver, qué hace decir y en qué términos, qué genera, intentado dar cuenta de lo que el mismo, en tanto huella, es y produce. Quisiera concluir -más bien recomenzar-con aquello que el 
documento no nombra y que, por lo mismo, constituye una fuente privilegiada de poder. La obliteración de la escritura represiva se da en varios sentidos: la más obvia se trata del autor, y paradójicamente omnipresente. La segunda oculta una localización, una referencia institucional que constituyó la "novedad" del poder desaparecedor (Calveiro, 2001) durante la última dictadura: el Centro Clandestino de Detención. Luego, se cubren de eufemismos o se omiten las prácticas más comprometedoras del funcionamiento concentracionario - la tortura, llamada "interrogatorio", el asesinato -. Por último, habla sobre las acciones de víctimas en una lengua represiva, clandestina que, al nombrarlos como "colaboradores", los inculpa, los hace asumir, o por lo menos compartir, la responsabilidad sobre los crímenes allí cometidos.

Este juego entre lo que se dice, lo que no, lo que se entredice, lo que se pre-dice es particularmente poderoso. A través de sus líneas, entre sus pliegues y silencios, en su diálogo con otras voces, el entramado entre saber y poder que el documento muestra permite analizar su relación con las prácticas represivas, su potencial disciplinador y performativo en la creación de categorías identitarias con características de estigma. También, en estos entramados entre saber y poder, se pone de relieve el rol de la visibilidad de las prácticas represivas y el "entrever" que las mismas proponían a la población como fuente de control territorial a partir del terror.

67 Los Centros Clandestinos de Detención fueron, principalmente, dispositivos de administración de necropolíticas: de un poder soberano capaz de hacer morir. Poder que en este documento es totalmente obliterado, ya que no menciona el destino final de miles y miles de prisioneros. Pero si un documento así fue producido, con la necesidad de plasmar, de hacer ver un saber, es porque su poder no se agota allí. Cabe preguntarse, a la luz de lo visto en este desarrollo, no solo por lo que ese poder destruyó, sino también por lo que produjo e incluso reprodujo a través de sus silencios. Saber, poder y subjetividad se entraman entonces en la producción de un disciplinamiento con efectos duraderos que, cada vez que se hace ver, lo hace fragmentaria y parcialmente y, por lo mismo, incita y aterra.

68 A modo de conclusión, quisiera retomar cómo el documento explicita un sistema de control a partir de una amalgama en la administración del tiempo y el sufrimiento. Un tiempo minuciosamente gestionado del que la escritura forma parte, ya que permite objetivar su poder, prolongarse indefinidamente, trascender los límites espaciotemporales del Centro Clandestino. El agente de inteligencia ¿tendría clara esta proyección? Matar a muchos, dejar vivir a algunos, ocultar, pero también hacer saber el terror que fueron capaces de infundir deja planteadas preguntas que quizás nunca obtengan respuesta.

69 Al leerlo, se replica el efecto de aquella sensación de sujeción ante el poder concentracionario - hay cosas que ellos saben y que nunca sabremos-, la sentencia sobre el poder de saber y el poder de hacer ver que vaticina el documento: "que en el momento de la caída del militante, se le puede mostrar que se lo conoce (...) esto 'descoloca' al detenido y facilita el quiebre rápido del mismo". El saber, el panóptico, disciplina y, en un extremo, "quiebra" al secuestrado. Y en cierta forma también al que lo descubre y lo lee. Como por accidente, como yo lo hice. Porque al leerlo, al tenerlo entre manos, ese juego siniestro que exhibe una mirada anónima, omnisciente y ubicua, lo vuelve un fetiche de un aura singular y oscura.

70 Agradecimientos: los avances de este texto fueron discutidos en las Jornadas de Historia Reciente (2018) y en el marco del proyecto "Perspectivas etnográficas sobre las 
memorias de la represión y la violencia política en el pasado reciente: cuerpos, identidades y territorios" (SeCyT-UNC). Agradezco los generosos aportes brindados en esas instancias, por los evaluadores y a Mariana Sirimarco por su atenta lectura.

\section{BIBLIOGRAPHY}

Bourdieu, P. (2002). ¿Qué significa hablar? Economía de los intercambios lingüísticos. Madrid: Editora Nacional.

Bussi, A. D. y Bussi, J. L. (2011). Mi padre: el general. Tucumán: Ed. Del autor.

Calveiro, P. (2001). Poder y desaparición. Buenos Aires: Ed. Colihue.

Calveiro, P. (2006). Testimonio y memoria en el relato histórico. Acta poética $\mathrm{N}^{\circ} 27$, otoño. 65-86.

Contepomi, G. y Astelarra, P. (1984). Sobrevivientes de La Perla. Córdoba: El Cid Editor.

Derrida, J. (1997). Mal de archivo. Una impresión freudiana. Montevideo: Trotta.

Elias, N. (2001). El proceso de la civilización. México: Fondo de Cultura Económica.

Farge, A. (1991). La atracción del archivo. Valencia: Edicions Alfons el Magnanum, Institució Valenciana de Estudios e Investigació.

Favret-Saada, J. (2009). Etre affectée. Désorceler, (pp. 145-161). París: Editions de l'olivier.

Feld, C. y Salvi, V. (Comps.) (2019). Las voces de la represión: declaraciones de perpetradores de la dictadura argentina. Ciudad Autónoma de Buenos Aires: Miño y Dávila.

Feld C., Salvi V., Larralde Armas, F., D' Ottavio, A., Diz, M. (2016). Los represores como objeto de estudio. Obstáculos, problemas y dificultades para su investigación en la Argentina, (pp. 22-40). Buenos Aires: Cuadernos del IDES.

Foucault, M. (1996). Genealogía del racismo. La Plata: Ed. Altamira.

Foucault, M. (1997). Historia de la sexualidad. La voluntad de saber. México: Siglo XXI Editores. Foucault, M. (1990). La vida de los hombres infames. Madrid: Editorial La Piqueta.

Freud, S. (1992). Obras completas. Tomo VII. Buenos Aires: Amorrortu.

Geertz, C. (2001). La interpretación de las culturas. Madrid: Grijalbo.

Ginzburg, C. (2003). Tentativas. Michoacán: Universidad Michoacana de San Nicolás de Hidalgo.

Gillespie, R. (2011). Soldados de Perón: historia crítica de los Montoneros. Buenos Aires: Sudamericana.

Krotz, E. (1994). Alteridad y pregunta antropológica. Alteridades, 4(8), 5-11.

Malinowski, B. (1973). Los argonautas del Pacífico occidental. Barcelona: Ed. Península.

Mbembe, A. (2011). Necropolítica. España: Melusina.

Neiburg. F. (1995). El 17 de Octubre de 1945: Un análisis del mito de origen del peronismo. En J. C. Torre. (Comp.), El 17 de Octubre de 1945, (pp. 219-283). Argentina: Ed. Espasa Calpe. 
Pollak, M. (2000). L'expérience contrationnaire. París: Métailié.

Pollak, M. (2006). Memoria, Olvido, Silencio. La producción social de identidades ante situaciones límite. La Plata: Al Margen.

Olmo, D. (2002). Reconstruir desde restos y fragmentos. El uso de archivos policiales en la antropología forense en Argentina. En E. Jelin y L. Da Silva Catela (Comps.), Los archivos de la represión: Documentos, memoria y verdad (pp. 179-194). Madrid: Siglo XXI editores.

Olmo, D. y Somigliana, M. (2002). Qué significa identificar. http://www.equiponaya.com.ar/ congreso2002/ponencias/dario_olmo.htm. Última consulta 3 de agosto de 2019.

Pontoriero, E. (2017). Excepcionalidad jurídica y contrainsurgencia: claves para pensar la racionalidad militar en los inicios del terror de Estado en Argentina (1973-1976). Páginas, 9(19), 53-74.

Pontoriero, E. (2015). "Preparativos de guerra": Ejército, doctrina antisubversiva y planes represivos en los orígenes del terror de Estado, 1973-1976. RUHM, 5, 319-339.

Risler, J. (2019). Acción psicológica: tecnología de persuasión de la última dictadura argentina. Bordes, 151-158.

Risler, J. (2018). La Acción psicológica. Dictadura, inteligencia y gobierno de las emociones (1955-1981). Buenos Aires: Tinta Limón.

Robben, A. (2011). Seducción etnográfica, transferencia y resistencia en diálogos sobre terror y violencia en Argentina, Altheia, 1(2).

Salvi, V. (2015). Guerra, subversivos y muertos. Un estudio sobre las declaraciones de militares en el primer año de democracia. En C. Feld y M. Franco (Dirs.), Democracia, hora cero. Actores, políticas y debates en los inicios de la posdictadura, (pp.153-194). Ciudad Autónoma de Buenos Aires: Fondo de Cultura Económica.

Schindel, E. (2013). Ghosts and compañeros: haunting stories and the quest for justice around Argentina's former terror sites. Rethinking History: The Journal of Theory and Practice, 18(2), $2-23$.

Sirimarco, M. (2013). El policía y el etnógrafo (sospechado): disputa de roles y competencias en un campo en colaboración. Etnográfica, 16(2), 269-290.

Tello, A. M. (2016). Foucault y la escisión del archivo. Revista de Humanidades, 34, 37-61.

Tello, M. (2012). La Vida en Fuego. Un análisis antropológico sobre las memorias de la 'lucha armada' en los '70 en Argentina. Tesis doctoral en Antropología. Universidad Autónoma de Madrid, España.

Tello, M. (2018). Morir en vida" Estados de existencia en las experiencias concentracionarias. Revista Avá, 30, 81-104.

Turner, V. (1990). La selva de los símbolos. Madrid: Siglo XXI Editores.

Van Roeckel, E. (2016). Phenomenal Justice: State violence, emotion and the law in Argentina. Hertohenbosch: ABC's.

Vergez, H. (1995). Yo fui Vargas. El antiterrorismo por dentro. Buenos Aires: Edición del Autor.

\section{Documentos:}

Caso 68, p.34. Fondo Documental SIDE, APM. 
Dossier de la Mega Causa La Perla (2012). Informe sobre el juicio al terrorismo de Estado en Córdoba. Comisión Provincial por la Memoria.

Robin, M. M. (2003) Los escuadrones de la muerte. La escuela francesa.

Romero, V. y Garzón, B. (2007) El alma de los verdugos.

Testimonio de Liliana Callizo ante el Consulado Argentino en Bilbao, España, marzo de 1984.

Testimonio de Teresa Meschiati, Legajo CoNaDeP 4279, diciembre de 1983.

\section{NOTES}

1. El presente artículo deriva de una ponencia presentada en las IX Jornadas de Trabajo sobre Historia Reciente (2018).

2. El proyecto se titula "Militar, caer, sobrevivir: Memorias e identidades en torno al ejercicio y el padecimiento de la violencia política en los '70", que desarrollo como investigadora científica en el Consejo de Investigaciones Científicas y Tecnológicas (CONICET) y en continuidad con la labor realizada desde 2008 como parte del área de investigación del Espacio para la Memoria, ex CCDTyE "La Perla”, Córdoba, Argentina.

3. La Perla se emplazó al interior de los campos del III Cuerpo de Ejército, a la altura del $\mathrm{km} 12$ 1/2 de la ruta nacional 20, que conduce a la localidad serrana de Villa Carlos Paz. La Perla funcionó como Centro Clandestino de Detención, Tortura y Exterminio entre el 24 de marzo de 1976 y fines de 1978, bajo la órbita del Comando del III Cuerpo de Ejército y dependiente del Destacamento de Inteligencia 141 "General Iribarren". Durante ese tiempo "pasaron" por La Perla entre 2300 y 2500 personas, continuando la mayor parte de ellas desaparecidas. En 2007 el predio fue retirado de la órbita del Ejército y destinado a ser un Espacio para la Memoria, inaugurándose como tal el 24 de marzo de 2009.

4. De ahora en más utilizaré la tipografía en itálica para destacar las categorías teóricas o analíticas, y comillas para hacer lo propio con las categorías nativas o de los actores.

5. Al margen del silencio estratégico que, en las categorías nativas responde a la combinación de un "pacto de sangre" con un - posterior- "pacto de silencio", los "represores" han relatado diferentes aspectos de sus experiencias en algunos momentos. Así, encontramos algún escrito autobiográfico, como es Yo fui Vargas (1995) del ex agente de inteligencia Héctor Pedro Vergez, y cuasi biográfico como Mi padre, el general, escrito por José Luis Bussi (2011), en base a las conversaciones con su padre, Antonio Domingo Bussi. También algunos documentales, como es el caso de Los escuadrones de la muerte, la escuela francesa (2003) de la francesa Marie Monique Robin y El alma de los verdugos (2007) de los españoles Vicente Romero y Baltazar Garzón, donde los represores dan algunos detalles sobre los fundamentos de la represión. Otros casos, muy minoritarios, son los de los llamados "arrepentidos": el más famoso fue Adolfo Scilingo, quien en 1995 confesó en una entrevista haber arrojado personas al río de la Plata y, por último, las declaraciones públicas de los mismos en el marco de los juicios que se realizaron desde la restauración de la democracia en 1983. Por otro lado, existe un campo de investigación incipiente en torno a este tema, en el que se puede mencionar los trabajos de Robben (2011), Van Roeckel (2016), Salvi (2015), Feld et. al. (2016) y Feld y Salvi (2019).

6. Como muestran los trabajos de Pontoriero, el Ejército lleva produciendo material doctrinario para la "lucha contra la subversión" desde los años 50. Sin embargo, este material ofrece directivas generales - tal como el propio término "doctrina" indica- y no documentación del accionar directo de las Fuerzas. Este material, entonces, debe ser complementado con otros. En los testimonios de sobrevivientes que fueron obligados a realizar tareas administrativas durante su cautiverio en La Perla, consta que en este CCD se confeccionaron listas de prisioneros por 
triplicado, entre otro tipo de documentación como fichas o documentos estratégicos, los cuales son inaccesibles en la actualidad.

7. Las fichas responden a un formato de catalogación de inteligencia más clásico: contienen nombres, datos personales, fotos, antecedentes penales y actividades políticas de las personas. Muchos de ellos refieren a un rango temporal mucho mayor que el de la dictadura -por ejemplo, una enorme cantidad de esas fichas consignan información sobre viejos militantes del Partido Comunista- siendo sumamente iluminadoras de persecuciones políticas desde la perspectiva de la larga duración.

8. Según la definición del diccionario oxford, un caso es una "palabra genérica que hace referencia a una situación, suceso, acontecimiento, conjunto de circunstancias, etc., entendidos como una entidad particular y diferenciada". Los casos incluidos en estas carpetas, contienen en su interior colecciones de papeles referidas a algún grupo, que se van acumulando siguiendo la lógica administrativa de recolección paulatina de información.

9. La SIDE formó parte de la Comunidad Informativa (CI), órgano de coordinación comandado por el Ejército que reunía a las diferentes fuerzas de seguridad y a los responsables de las subzonas del Ejército encargadas de la represión. En Córdoba la CI comenzó a funcionar con una frecuencia semanal a finales de 1975, momento en el que se crea la estructura de inteligencia que llevaría adelante la represión. La SIDE, así como la Policía Federal, no aparecen dentro de esa estructura como agencias "operativas" (cosa que se confirma en los relatos de los sobrevivientes) sino que parecen haber ocupado un rol de registro y archivo de la información compartida. Esto último explicaría la presencia de este documento entre los "casos", probablemente proveniente de algún otro organismo encargado de sistematizar la información "táctica".

10. En La voluntad de saber Foucault (1997) advierte sobre la tensión entre la producción discursiva, la producción de poder y la producción de saber. El imperativo desde las instituciones de hablar sobre una práctica (en el caso que analiza es el sexo, pero también puede aplicarse a la práctica "contrainsurgente") en sus propios términos -eufemizando, mostrando y ocultando, como veremos en adelante- constituye otra forma de ejercicio del poder.

11. En torno a la relación entre poder y saber señala Andrés Tello: "la complementariedad entre ambos ejes de las investigaciones de Foucault - las formas del saber y las relaciones de poderestá dada por una diferencia fundamental, mientras la arqueología remite a un procedimiento descriptivo de los regímenes del saber, en el caso de la genealogía estamos frente a un procedimiento que explica el diagrama de fuerzas que da forma a lo que se "hace ver" y se "hace decir". Junto al movimiento que va de un procedimiento al otro, lo importante para nosotros es que la noción de archivo se traslada sigilosamente, pues ambos procedimientos son suplementarios" (2016, p. 48).

12. Achille Mbembe (2011) desarrolla el concepto de necropolitica para problematizar el de biopolitica acuñado anteriormente por Michel Foucault (1996). Foucault destaca el poder desarrollado por los Estados modernos para el control de las poblaciones. El biopoder $-\mathrm{y}$ su capacidad de "hacer vivir y dejar morir", o cuidado de la vida- se centra en el conocimiento y el entrenamiento de los cuerpos con el fin de volverlos útiles. Mbembe complejiza el planteo sobre el biopoder a la luz del contexto poscolonial, donde los Estados periféricos -diferentes a los que analiza Foucault- superponen el poder de "hacer vivir y dejar morir" en pos de generar cuerpos productivos, con una suerte de "poder soberano" con potestad de "hacer morir y dejar vivir" de modo selectivo. Así como el biopoder es un gobierno sobre la vida, el necropoder se transforma en una homóloga administración estatal de la muerte. Si bien el fin último de los CCD destinados al exterminio fue matar a la disidencia política, adoptaré aquí esos términos para hablar de dos polos que convergen en las prácticas de disciplinamiento de aquellos que dejaron vivir y que, a su vez, construyen otro imperativo de hablar, de testimoniar. Los efectos destructivos y productivos del "campo" están, en estos casos, en permanente tensión, de modo que hablo aquí de la 
experiencia que emana de la administración de la muerte, pero que debe ser combinada con un análisis del gobierno de la sobre-vida.

13. Al respecto de lo que (me) provoca el hallazgo de un documento de estas características, hago mías las palabras de Arlette Farge cuando plantea que "con nada se puede describir el efecto de realidad que se siente mejor que con esos (...) objetos encontrados al azar en las consultas de los informes (...) Por otra parte, la invasión de esas sensaciones nunca dura, dice que sucede lo mismo con los espejismos. Por mucho que lo real parezca estar ahí, visible y aprehensible, nunca dice nada más a sí mismo y es una ingenuidad creer que ahí se ha reducido a la esencia" (Farge, 1991, pp.13-14).

14. En la colección de carpetas en las que se encuentra el caso, los números a veces se repiten, o no son consecutivos, o han sido reasignados. Esto, sumado a la variabilidad del material que contienen, hace difícil ubicar los "casos" en un orden cronológico o incluso deducir con qué fines -más que la acumulación- fue recopilada la información. El fotocopiado sugiere que el documento no fue elaborado por la propia SIDE (la cual presenta muchas otras carpetas con material original) y su reasignación -de caso 44 a 68-, que el mismo varió en importancia con el tiempo.

15. La imagen del horrocrux, tomada de la saga "Harry Potter", de J. K. Rowling, es lo que mejor describe el tipo de afectación que me produjo el documento-objeto y las pesadillas persecutorias que me acecharon por las noches tras los días de lectura. En la saga, los horrocrux son objetos donde un mago, en este caso uno que encarna el mal, "el que no debe ser nombrado", ha distribuido partes de su alma con el fin de lograr la inmortalidad. El horrocrux, como nuestro documento, es poderoso, parcial y opaco. La definición no difiere mucho del talismán, o de los numerosos objetos dotados de magia (de mana) en la antropología clásica, que parecen estar investidos de un poder, provenientes de una persona con poder análogo y con efectos sobre otros. Por lo dicho, la figura me pareció pertinente en relación no solo con el objeto en sí, sino a mí como lectora posicionada y capaz de unir ese objeto con otras piezas.

16. El anónimo (escrito sin nombre, sin autoría) es un género muy particular. En la antigüedad el género obedecía a la creación colectiva y transmitida oralmente. Luego, se utilizó para la publicación de textos en donde o bien el tema, o bien el autor, debían ser censurados de algún modo. En una versión más sintética, el anónimo se usa para dejar una advertencia, cuando no una amenaza, sin comprometer al enunciador. Prohibición, misterio y clandestinidad, escisión del agente y del enunciado como características hacen del anónimo un acto de comunicación incompleto que da un plus de poder al mensaje, y al objeto en sí (Schindel, 2013).

17. Ginzburg habla del paradigma indiciario como un método que se vale del desciframiento de signos de diverso tipo, "se basa en casos individuales proponiendo el carácter indirecto, indiciario y conjetural del conocimiento histórico" (2003, p. 117).

18. Un dato curioso $-\mathrm{y}$ otro indicio de la disputa de sentidos que establece el autor del documento al escribirlo- es que este no fue el nombre de la organización en ningún momento de su historia. La denominación de "Partido revolucionario" recuerda más al Partido Revolucionario de los Trabajadores (PRT), otra organización político-militar de gran envergadura, pero de un marxismo mucho más ortodoxo que Montoneros. Montoneros, en términos de estructura, contaba con un partido y un ejército, pero se calificaba a sí mismo como "Movimiento Peronista Montonero" (Gillespie, 2011) o simplemente "Montoneros".

19. Tello, Mariana (2012) "La vida en fuego. Un análisis antropológico sobre las memorias de la 'lucha armada' en los '70 en Argentina”, Doctorado en Antropología Social, Universidad Autónoma de Madrid (España). En esta investigación analicé cómo los ex militantes de organizaciones político militares recuerdan las experiencias de "lucha armada" en "los "70" y desde qué identidades políticas lo hacen. En la misma, abordé el "mundo" de las organizaciones clandestinas, y cómo el mismo reconfiguró en forma duradera aspectos estructurales de la cultura como son las nociones de tiempo, espacio y persona, centrándome ante todo en la noción 
de identidad y de sus transformaciones con relación a la violencia política padecida o ejercida alternativamente por estos grupos y personas.

20. Un interesante aporte acerca de las similitudes y diferencias entre etnógrafos y agentes de inteligencia y la naturaleza de una u otra práctica de indagación se encuentra en el trabajo de Sirimarco (2012).

21. Utilizo aquí la conocida expresión de Malinowski (1973) sobre los aspectos más estables de la organización social de un grupo, de los cuales el etnógrafo está llamado a dar cuenta por medio de cuadros. El índice, en este sentido, es una expresión sintética que da cuenta de un orden simbólico en el cual se establecen elementos principales y subsidiarios dentro de la vida social de la comunidad en cuestión.

22. Según Pontoriero, "Los militares pensaban su tarea represiva como un acto de combate propio de una 'guerra antisubversiva' en un contexto de emergencia avalado por la legislación. El corolario de ese proceso fue que las acciones criminales que estuvieron en el núcleo del terror estatal se asimilaron a un conjunto de operaciones de guerra ejecutadas para combatir a la “subversión”' (Pontoriero, 2017, p. 69).

23. Quizás esta estrategia de infiltración, que no es mencionada ya que el manual refiere más bien a procedimientos "operativos", sea la principal fuente de información del documento.

24. Este juego de identificación y alteridad, tanto como la disputa de la categoría "pueblo", que en contexto argentino es sinónimo de peronismo (Neiburg, 1995), el interés por Montoneros y el énfasis en la "infiltración" en el "pueblo", hace pensar en que el que escribió el documento es una persona de adherencia al peronismo, y en particular al peronismo de derecha, el cual calificó de "infiltrados en el movimiento" a las corrientes de orientación marxista. En La Perla, se daban constantemente estas discusiones entre dos de los agentes de inteligencia de alto rango y algunos militantes montoneros seleccionados, en base a su rango en la organización -oficiales- entre otras cosas para "discutir" con ellos.

25. El "lancheo" fue una práctica que consistía en llevar a prisioneros, luego del secuestro y tras la primera sesión de tortura, a las "citas" que tenían ese día, a fin de que fueran reconocidos por las personas con las que se tenía que encontrar y generar nuevos secuestros. También se hacía con posterioridad, sacando a secuestrados a lugares muy concurridos (galerías, partidos de fútbol, festivales de música) "a la pesca" de algún militante que los reconociera. Si bien en el documento $-\mathrm{y}$ en la jerga concentracionaria- se llama a esto "marcar", poniendo en el secuestrado la agencia de señalar, esto no da cuenta por completo de la situación, en principio porque se trataba de una práctica bajo un apremio extremo y después porque en la mayoría de los casos aunque los sacados de "lancheo" hicieran todo lo posible por no reconocer a nadie mirando vidrieras, por ejemplo- eran reconocidos por otros que reaccionaban al verlos con vida. 26. Las estructuras de vigilancia constante -como en la figura arquitectónica del Panóptico de Bentham, en Foucault- "genera un estado consciente y permanente de visibilidad que garantiza el funcionamiento automático del poder" (Foucault, 2002, p. 204). Así, los dispositivos de control territorial permanentemente puestos en escena, el llamado -rozando el apremio- a la "colaboración" de los vecinos plasmado en este documento genera una ilusión de visibilidad omnipresente.

27. Los operativos "rastrillo" aluden a la acción de esta herramienta, la cual consiste en separar materia más "gruesa", o basura en el arado de la tierra. Estos operativos "rastrillaban" o "peinaban" los territorios casa por casa, buscando material o personas que coincidieran con la caracterización de "subversivos".

28. Esto resuena en algunas estrategias de propaganda mediática analizadas por Risler (2019) donde aparecen las Fuerzas, y en particular el Ejército como garantes de la paz y que se conforman como un conjunto de tecnologías de gobierno de la población, no ya para la gestión de la muerte, sino para el disciplinamiento y gestión de la vida. Esto se enmarcaba en la "acción psicológica”, consignada en algunos documentos castrenses como el Reglamento del Ejército RV 
136-1 (Terminología Castrense de Uso de las Fuerzas Terrestres), como medios para "influir sobre el campo síquico de determinado público" (citado en Pontoriero, 2015, p. 337).

29. Esta estrategia se nombra y describe minuciosamente en otros documentos que guardan enormes similitudes con respecto al análisis político, ideológico y militar de las organizaciones, aunque resultan más genéricos en las indicaciones, como el Reglamento (reservado) RC 9-1 "Operaciones contra elementos subversivos (proyecto)" de agosto de 1975 (citado en Pontoriero, 2015).

30. El mismo es muy esquivo, diría que hasta cuidadoso, en el establecimiento de estas huellas que permitirían identificar a su autor. Dentro de las marcas temporales que encontré "peinando" el documento, la más reciente en el tiempo es el ataque por parte de Montoneros a la Superintendencia de la Policía Federal el 2 de julio de 1976, lo cual si bien no permite datarlo con exactitud -puede haber sido confeccionado en cualquier momento posterior- permite hipotetizar que el mismo fue redactado en la segunda mitad de 1976, momento en que, además, comenzaban a agotarse los "blancos" de "superficie" (militantes fuera de la clandestinidad, que actuaban con mayor visibilidad) y pasaban a ser prioritarios los "cuadros" de las organizaciones armadas en la clandestinidad.

31. Risler $(2018,2019)$ ha analizado pormenorizadamente la llamada "acción psicológica" del gobierno de facto. Si bien en el documento se aplica tanto a las acciones destinadas a generar el control y consenso de la población como a las acciones de la organización Montoneros, el nivel de análisis del documento hace pensar en que alguno de los órganos encargados de una estrategia de tipo "psicosocial" puede haber desarrollado estudios para comprender la cultura militante.

32. Hijos e Hijas por la Identidad y la Justicia contra el Olvido y el Silencio es un organismo de DDHH que nuclea a hijos de las víctimas de la represión y a todo aquel que comparte sus lineamientos políticos.

33. En la llamada "Causa Acosta" (caratulada de ese modo en alusión a uno de los imputados) o "Causa de los sobrevivientes", se juzgó a 21 represores por los delitos de privación ilegítima de la libertad y aplicación de tormentos agravada cometidos contra 139 sobrevivientes.

34. Se refiere al agente de inteligencia Sto. Elpidio Tejeda, alias "Texas", célebre por haber sido entrenado en la Escuela de las Américas.

\section{ABSTRACTS}

The article analyzes the document called "Counterinsurgency from the Montoneros Revolutionary Party", which is included in the documentary collection "SIDE", in custody of the Provincial Archive of Memory in Cordoba. The document - which seems to be a handbook for a course- provides a unique understanding material of the so-called "counterinsurgent doctrine" that was applied as method in Argentina during the last dictatorship (1976-1983). This doctrine was the theoretical reference of the intelligence organisms of the repressive forces and was applied in the Clandestine Detention Centers. Throughout forty-three pages the document develops, in a detailed way, the readings about the sociopolitical conflict, as well as about the Montoneros organization as contending and the justification and foundation of the proposed repressive method. Subsequently, it provides directives about territorial control in the detection and capture of militants. Finally, it details the so-called "unconventional methods" applied by the repression once the militants have been captured, in order to achieve the "break" of the prisoners and the "fall" of new prisoners. Thus, in conceptual terms, the article analyzes the 
intertwined between knowing and power that the document reveals, and the relationship whit the repressive practices within the Clandestine Detention Centers and in their public side, and its disciplinary potential.

El presente artículo analiza el documento llamado "Contrainsurgencia a partir del accionar del partido revolucionario Montoneros", que consta en una carpeta incluida en el fondo documental "SIDE", en guarda en el Archivo Provincial de la Memoria, en Córdoba. El documento -que aparenta ser un manual o apunte para un curso- aporta un singular material de comprensión de la llamada "doctrina contrainsurgente" aplicada como metodología represiva en Argentina durante la última dictadura (1976-1983), que tuvo como referencia institucional los organismos de inteligencia de las fuerzas represivas y como ámbito de aplicación los Centros Clandestinos de Detención. A lo largo de cuarenta y tres páginas el documento desarrolla, de un modo detallado, tanto las lecturas en torno al conflicto sociopolítico, como a la organización Montoneros como contendiente y la justificación y fundamentación del método represivo propuesto. Posteriormente, da directivas en torno al control territorial en pos de la detección y captura de militantes. Por último, detalla los "métodos no convencionales" aplicados por la represión una vez capturados los militantes, para lograr el "quiebre" de los mismos y la "caída" de nuevos prisioneros. En términos conceptuales, el artículo aborda etnográficamente el entramado entre saber y poder que el documento muestra, su relación con el accionar represivo y su potencial disciplinador, tanto al interior de los Centros Clandestinos de Detención como en su faceta pública.

\section{INDEX}

Keywords: Counterinsurgency, disciplination, Clandestine Detention Centers, documents

Palabras claves: Contrainsurgencia, disciplinamiento, Centros Clandestinos de Detención, documentos

\section{AUTHOR}

\section{MARIANA TELLO WEISS}

Instituto de Antropología de Córdoba (Consejo Nacional de Investigaciones Científicas y Tecnológicas-Universidad Nacional de Córdoba), Argentina

marianatellow@gmail.com 